\title{
The effects of moisture and micro-structural modifications in drying mortars on vibration-based NDT methods
}

\author{
J. N. Eiras ${ }^{1}$, J.S.Popovics ${ }^{2}$, M.V. Borrachero ${ }^{1}$, J.Monzó ${ }^{1}$, J.Payá ${ }^{1}$ \\ ${ }^{1}$ Instituto de Ciencia y Tecnología del Hormigón. Universitat Politècnica de \\ València. Camino de Vera s/n, Edificio 4G, 46022 València. Spain. \\ ${ }^{2}$ Department of Civil and Environmental Engineering, University of Illinois, 205 \\ N. Mathews Ave, Urbana, IL, 61801, USA. \\ *Corresponding author: jeseifer@posgrado.upv.es
}

\section{Abstract}

In this paper, we investigate the utility of vibration-based NDT tests to detect the subtle microstructural modifications and cracking damage in portland cement mortars subjected to oven drying treatment. Both linear (resonant mode frequency and damping) and nonlinear (nonlinear hysteretic behavior) vibration test data are reported, collected from samples having a range of water to cement ratios and at two different aggregate contents. All test data are affected by the drying treatments, but it appears that the resonant mode frequency response is dominated by the reduction in internal moisture content with drying and changing aggregate cement ratio of the mixture. On the other hand, the linear mode damping, and more so the nonlinear hysteretic parameter, are more influenced by the microstructural modification and cracking damage caused by drying. In particular it appears that the nonlinear hysteretic parameter is very sensitive to internal damage and microstructural modifications caused by oven drying, but not notably sensitive to pore moisture content, and water to cement and aggregate to cement ratios.

Keywords: NIRAS, nonlinear acoustic, nondestructive test, drying shrinkage, mortar. 


\section{Introduction}

Cement-based materials are affected by changes in internal moisture content within

3 the pore structure, resulting in dimensional changes and tensile stresses that can

4 promote internal cracking. Two principal mechanisms cause internal moisture changes.

5 The first is that caused by autogenous shrinkage that occurs during cement hydration,

6 what especially occurs in low water to binder ratio mixtures (e.g. < 0.40) [1]. The

7 second is that caused by the removal of water from the cement matrix pore structure

8 driven by external evaporation what causes significant volumetric shrinkage of the

9 material, whose main mechanisms are disjoining pressure, capillary pressure and

10 changes in surface free energy [2]. In addition, since outer surfaces dry faster, moisture

11 gradients can be produced what lead into tensile cracking, and which in turn will be

12 enhanced in those materials with lower diffusion rates [REF]. With all, the extent of the

13 resulted microcracking shrinkage on drying, depends on the external geometrical

14 restraint conditions of the sample [3], the exposure conditions [4], the aggregate content

15 [5-7], and on the characteristics of the pore network [REF]. External evaporation can

16 further promote microstructural modification, such as an increase of the surface energy

17 what results in an increase of the bonding between particles of $\mathrm{C}-\mathrm{S}-\mathrm{H}$, even in the

18 absence of shrinkage cracking, under moderate oven drying temperatures (at and below

$19105^{\circ} \mathrm{C}$ ) [8].Moreover, Moukwa and Aïtcin [9] demonstrated that cement paste samples

20 oven dried at $105^{\circ} \mathrm{C}$ showed an increase in capillary-sized porosity (mainly in the range

21 from 0.01 to $0.1 \mu \mathrm{m}$ ), but no obvious signs of microcracking, where this effect became

22 more prevalent with decreasing w/c. Gallé [10] confirmed the findings of Moukwa and

23 Aïtcin for oven dried cement pastes, and further observed similar behavior in concrete

24 samples, but at lower oven drying temperatures $\left(60^{\circ} \mathrm{C}\right)$. 
The cracking potential of cement-based materials owing to drying is commonly

2 assessed by dilatometry based techniques, such as the ring test [11, 12]. Acoustic

3 emission-based monitoring has also been successfully applied to monitor

4 microstructural changes in cement-based materials owing to cement hydration and

5 setting [13, 14] and drying [15]. Although acoustic emission can be used to monitor

6 active transient events related to hydration, setting and drying, the method cannot be

7 applied to assess a sample after the specific processes have occurred; thus the method is

8 unable to characterize the existing damage level in a sample in situ, or to derive

9 constitutive properties of the material. Mechanical wave methods, such as ultrasonic

10 pulse velocity or vibration resonance, are sensitive to internal damage and constitutive

11 properties in cement-based materials [16]. However, conventional methods based on

12 linear mechanical wave propagation have rarely been used to monitor the

13 microstructural changes owing to desiccation, most likely because of the high degree of

14 sensitivity needed to detect such subtle characteristics in the materials. Recently,

15 nonlinear mechanical wave based methods have shown promise for enhanced detection

16 of cracking damage in concrete exposed to sustained temperatures greater than $100^{\circ} \mathrm{C}$

17 [17], and simulated damage in mortars [18].

In this paper, we further investigate the utility of nonlinear acoustic vibration based nondestructive tests to detect the subtle shrinkage microcracking produced in cement-

20 based materials on drying. For more comprehensive analysis, we consider both linear

21 and nonlinear vibration results. Mortar samples with varying aggregate to cement ratio

22 and water to cement ratio are subjected to an oven drying process at $60^{\circ} \mathrm{C}$. The oven

23 dried mortar samples are expected to exhibit reduced internal moisture content,

24 increased amounts of capillary sized porosity [9, 10], and microcracking damage [REF].

25 Furthermore, the samples with very low water to binder ratio are expected to exhibit 
1 exacerbated cracking, because of either: enhanced autogenous shrinkage or lower

2 diffusion rates producing nonuniform drying. On other hand, the mortars with greater

3 aggregate content are expected to restrain the development of microcracks produced on

4 the bulk shrinkage of the material after drying.

\section{2. Background Information}

6 Resonance vibration inspection techniques are based on the mechanical properties

7 of a finite sized body when it resonates at its natural frequencies. Under flexural motion,

8 the dynamic modulus of elasticity $\left(E_{d}\right)$ of a prismatic concrete sample supported at its

9 nodal points is given by [20].

$10 \quad \mathrm{E}_{\mathrm{d}}=\frac{4 \pi \cdot L^{4} \cdot f_{f}^{2} \cdot \rho \cdot 1.401}{4.73^{4} \cdot t^{2}}$,

11 where $f_{f}$ is the natural frequency corresponding to the first bending mode, $\rho$ is mass

12 density, $L$ is length, and $t$ is the radius of gyration of the sample. During a transient

13 resonance event, the sample loses mechanical energy with each successive vibration

14 cycle. This rate of mechanical energy loss is expressed through the quality factor (Q),

15 which is defined as the ratio between the resonance frequency peak $\left(f_{f}\right)$, and the

16 bandwidth frequencies $\left(f_{b}\right.$ and $f_{a}$ ) corresponding to a $50 \%$ reduction of vibration energy

17 in the power frequency spectrum [20]

18

$$
\mathrm{Q}=\frac{f_{f}}{f_{b}-f_{a}} .
$$

19 A reduction in $Q$ value is associated with an increase in material mechanical damping

20 losses, either caused by viscous, hysteretic, or other mechanisms.

21 Both, $E_{d}$ and $Q$ assume a linear stress-strain relationship and linear damping. However,

22 the presence of defects on the complex microstructure of cement-based composites 
1 across a range of length scales (microcracks, porosity, interfacial transition zones, etc.)

2 reveals the presence of so called non-classical nonlinear phenomena [21]. With this

3 behavior, a nonlinear modulus parameter should be used to describe hysteresis in the

4 stress-strain relationship. In resonance vibration tests, the nonlinear hysteresis behavior

5 manifests as a down shift of resonance frequency value with an increase in vibration

6 energy (normally represented as dynamic strain) amplitude; this is also referred to as the

7 “fast dynamics" effect. The hysteretic parameter $\alpha$ is related to the down shift of the

8 resonance frequency $(\Delta f)$ with increasing strain amplitude $(\Delta \varepsilon)$ by [22]

$9 \quad \frac{\Delta f}{f_{o}}=\alpha \cdot \Delta \varepsilon$

where $f_{0}$ is a low amplitude linear resonance frequency value that is used as a

11 comparative standard. The hysteretic parameter $\alpha$ can be obtained using an experimental configuration known as Nonlinear Impact Resonance Acoustic Spectroscopy (NIRAS). NIRAS is carried out by applying a set of impulse based vibration tests with progressively increasing impact energy, and monitoring the change (reduction) in resonant frequency. NIRAS has been applied to characterize a wide range 16 of damage mechanisms in cement-based materials [23-25]. In this study, we apply linear vibration tests [26] and NIRAS to study the effect of desiccation in mortars.

\section{Experimental Investigation}

Mortar samples of dimension 40 x 40 x 160 mm and with varying composition were produced. Series “I” comprises samples with aggregate to cement ratio $(a / c)$ of 3

21 with water to cement ratio (w/c) varying from 0.40 to 0.65 . Series "II" comprises 22 samples with $a / c$ of 1 with $w / c$ varying from 0.25 to 0.45 . The portland cement used was type CEM II 42.5R/A-L. A siliceous aggregate was used with sieve size distribution 
1 following the recommendation in the standard EN 196-1 [27]. The lowest w/C

2 specimens within both series (I-0.40 and II-0.25) were prepared with a $1 \%$ by weight of

3 a sulphonated melamine-based superplasticizer to obtain a workable consistency. Six

4 samples of each mortar designation were produced and tested. Dry bulk density and

5 open porosity were ascertained from saturated, immersed and dried weights. One

6 additional mortar replicate set (three samples per type of mortar) was produced to

7 determine compressive strength at the age of 28 days after mixing. Table 1 summarizes

8 the mortar designations, mix proportions and physical properties such as slump, open

9 porosity, dry bulk density and compressive strength at 28 days.

10 Table 1. Mortar designation, mixture proportions and physical properties in fresh and 11 hardened states.

\begin{tabular}{|l|l|l|l|l|l|}
\hline Designation & Cement/Water/Sand & Slump, mm & $\begin{array}{l}\text { Dry bulk } \\
\text { density, } \\
\text { g/cm }\end{array}$ & $\begin{array}{l}\text { Open } \\
\text { porosity, } \\
\%\end{array}$ & $\begin{array}{l}\text { Compressive } \\
\text { strength at 28 } \\
\text { days } \\
\text { MPa }\end{array}$ \\
\hline I-040 & $1: 0.40: 3$ & $131 \pm 5$ & $2.14 \pm 0.01$ & $11.4 \pm 0.5$ & $65.41 \pm 1.84$ \\
\hline I-045 & $1: 0.45: 3$ & $120 \pm 5$ & $2.12 \pm 0.01$ & $12.9 \pm 0.6$ & $54.86 \pm 2.98$ \\
\hline I-050 & $1: 0.50: 3$ & $155 \pm 9$ & $2.06 \pm 0.01$ & $15.0 \pm 0.4$ & $53.85 \pm 1.36$ \\
\hline I-055 & $1: 0.55: 3$ & $190 \pm 11$ & $2.05 \pm 0.01$ & $17.2 \pm 0.3$ & $52.65 \pm 1.84$ \\
\hline I-060 & $1: 0.60: 3$ & $222 \pm 11$ & $2.05 \pm 0.01$ & $18.0 \pm 0.5$ & $49.97 \pm 2.35$ \\
\hline I-065 & $1: 0.65: 3$ & $245 \pm 6$ & $2.03 \pm 0.02$ & $19.3 \pm 0.8$ & $40.30 \pm 2.96$ \\
\hline II-025 & $1: 0.25: 1$ & $150 \pm 6$ & $2.21 \pm 0.01$ & $8.7 \pm 0.8$ & $83.04 \pm 3.55$ \\
\hline II-030 & $1: 0.30: 1$ & $146 \pm 6$ & $2.17 \pm 0.01$ & $10.3 \pm 1.3$ & $74.93 \pm 3.48$ \\
\hline II-035 & $1: 0.35: 1$ & $187 \pm 6$ & $2.05 \pm 0.01$ & $17.4 \pm 1.0$ & $68.14 \pm 2.00$ \\
\hline II-040 & $1: 0.40: 1$ & $225 \pm 8$ & $2.03 \pm 0.01$ & $18.3 \pm 0.4$ & $62.25 \pm 2.28$ \\
\hline II-045 & $1: 0.45: 1$ & $246 \pm 8$ & $1.96 \pm 0.01$ & $21.9 \pm 1.3$ & $57.31 \pm 2.52$ \\
\hline
\end{tabular}

12 
The samples were tested at two moisture conditions: fully saturated and oven dried.

2 All samples were immersed in $20^{\circ} \mathrm{C}$ water for more than 28 days after mixing. Under

3 these conditions, we expect the pore structure of the mature mortar to be fully saturated

4 with water. The samples were removed from the water bath and subjected to linear

5 vibration and NIRAS tests. Then the samples were oven-dried at $60^{\circ} \mathrm{C}$ until their mass

6 remained constant $( \pm 1 \mathrm{~g})$, removed from the oven, allowed to cool naturally during 24

7 hours to room temperature and at ambient relative humidity, and subjected to linear

8 vibration and NIRAS tests again.

9 The linear vibration tests were conducted following the standard resonance

10 vibration test configuration to promote flexural mode of vibration, according to ASTM-

11 C215:08 [26]. Linear dynamic modulus of elasticity $\left(E_{d}\right)$ was determined using Eqn. 1.

12 The linear quality factor $(Q)$ was computed from the data following the procedure

13 shown in Eqn. 2. The average of ten repeated relatively low energy impacts were

14 obtained for each sample and test. The bulk density, obtained by weighing the samples

15 at saturated and dried states, was used in the computation of $E_{d}$ at both saturation states:

16 fully saturated and after oven drying.

17 The vibrational response of the samples was sensed with an accelerometer: PCB

18 model 352A21 with a sensitivity of $0.956 \mathrm{mV} /\left(\mathrm{m} . \mathrm{s}^{-2}\right)$. For the NIRAS tests, an

19 instrumented hammer (PCB model Brüel \& Kjær 8206, $22.7 \mathrm{mV} / \mathrm{N}$ ) is used to strike the

20 samples at ten different energy levels. The relative position between impact and

21 accelerometer used in this study, allows simultaneous monitoring of the fundamental

22 bending and longitudinal resonant modes of vibration. Figure 1 shows the schematic test

23 configuration employed for the NIRAS tests, typical hammer load step, and the

24 resulting frequency spectra showing the two fundamental resonant peaks. 
1 From the acceleration amplitude, the strain amplitude can be approximatively obtained

2 using the analytical solution of a free-free beam [Abeele JONE]. In the study conducted

3 herein, the acceleration was converted to strain using a numerical simulation of the test

4 configuration (results not shown here) similarly to the method described on [28].

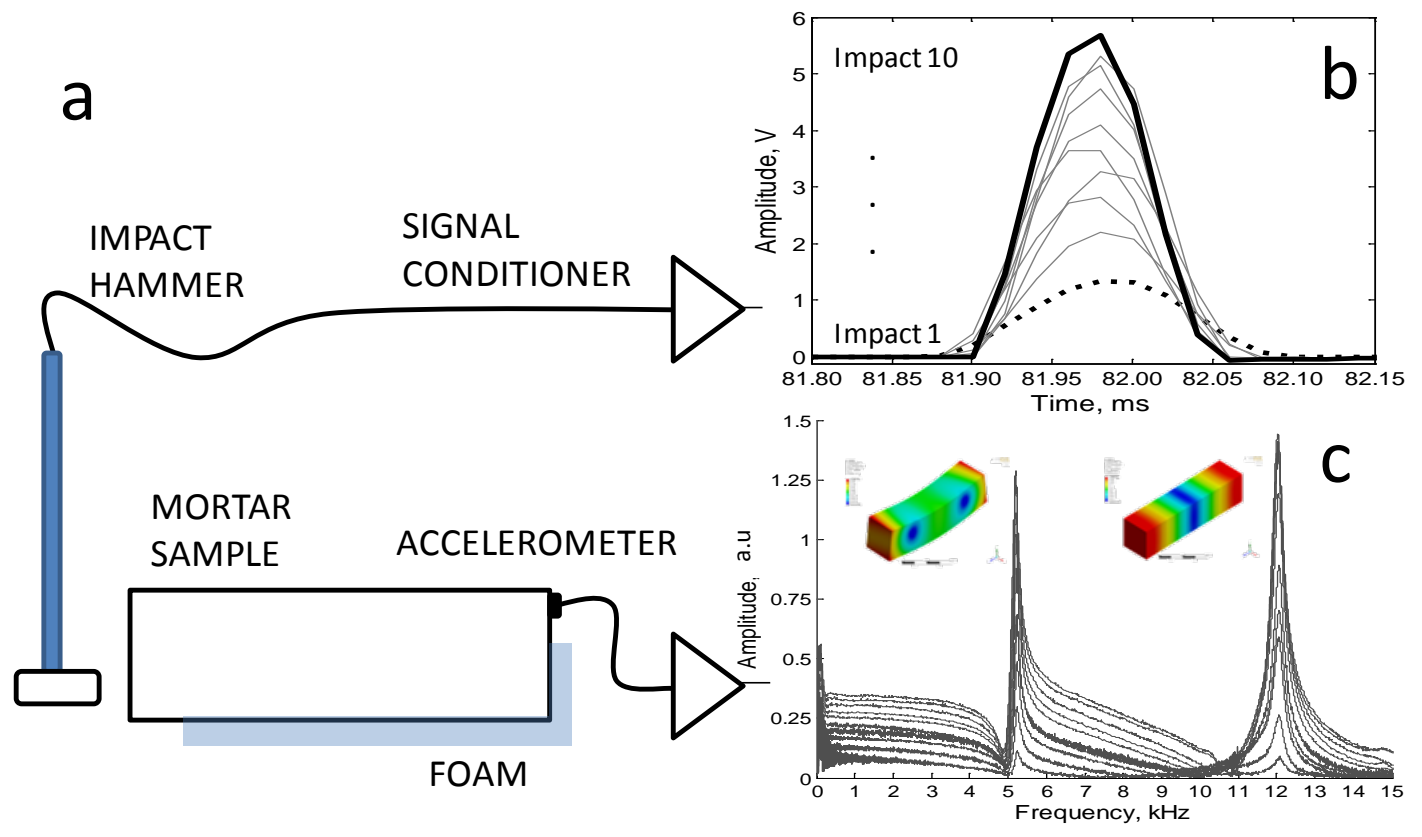

Figure 1. a) Schematic setup for NIRAS, note off-center impact location and

7 sensing in the sample, b) typical incrementally increasing hammer load responses

8 applied to samples, and c) typical received frequency spectra showing two resonance

9 modes:, fundamental bending mode (5-6 kHz) and fundamental longitudinal mode (11-

$1013 \mathrm{kHz}$ ); inset images illustrate respective modal vibration shapes of each mode.

\section{Results}

Figure 2a shows the values of $E_{d}$ as a function of $w / c$ at the saturated and dried states. It can be seen that $E_{d}$ decreases with increasing $w / c$ regardless of internal

14 moisture condition and mixture composition, confirming expected behavior [20]. The

15 change of $E_{d}$ with respect to moisture removal with drying was found to be dependent 
1 on both $w / c$ and $a / c$. To better understand this behavior, the relative reduction of $E_{d}$ after

2 oven drying can be expressed as

$3 \quad \% R E=\left(1-\frac{E d_{S=0}}{E d_{S=1}}\right) \cdot 100$

4 where $E_{d(s=1)}$ is the dynamic modulus in the pristine saturated state, and $E_{d(s=0)}$ that after

5 oven drying. Figure $2 \mathrm{~b}$ shows values of the relative reduction of $E_{d}(R E)$ after drying.

6 Except for the $\mathrm{w} / \mathrm{c}=0.25$ sample, the results demonstrate that higher $\mathrm{w} / \mathrm{c}$ mortars

7 experience more reduction in $E_{d}$ after drying for a given $a / c$ value. Similar behavior has

8 been reported for static modulus of elasticity measured on mortars with different $w / C$

9 content after drying [29], and most plausibly is a result of the increased capillary

10 porosity content obtained with increasing $w / c$. Similar conclusions can be drawn from

11 the reduction of dynamic modulus observed after drying, on concrete batches with

12 different amounts of capillary porosity [Yaman].The anomalous behavior of the

$13 \mathrm{w} / \mathrm{c}=0.25$ samples is addressed in the Discussion section below. The moisture inside of

14 a pore network affects the measured global stiffness of the material. This pore water-

15 induced stiffening effect appears to be dependent on pore size distribution, where

16 capillary-sized pore networks demonstrate a strong influence on such behavior [29, 30].

17 The results shown in Fig $2 \mathrm{~b}$ demonstrate that the reduction of dynamic modulus upon

18 drying is also dependent on $a / c$. In particular, the values of $R E$ obtained on mortars with

$19 a / c$ of 3 are greater than those obtained on mortars with $a / c$ of 1 . For instance, mortars I-

$20 \quad 060$ and II-040 have similar open porosity of about $18 \%$, though the $R E$ values are $15 \%$

21 and 7.5\%, respectively. The presence of aggregates endows a more open pore structure

22 at the interfacial transition zone (ITZ), compared with the bulk cement paste [31], such

23 that the volume of capillary-sized pore networks increases with increasing aggregate

24 content [32]. Therefore, greater values of $R E$ for mortars with $a / c=3$ as compared with 
1 those with $a / c=1$ can be attributed to the expected increased capillary and ITZ pore

2 volume that is expected from increased aggregate volume.
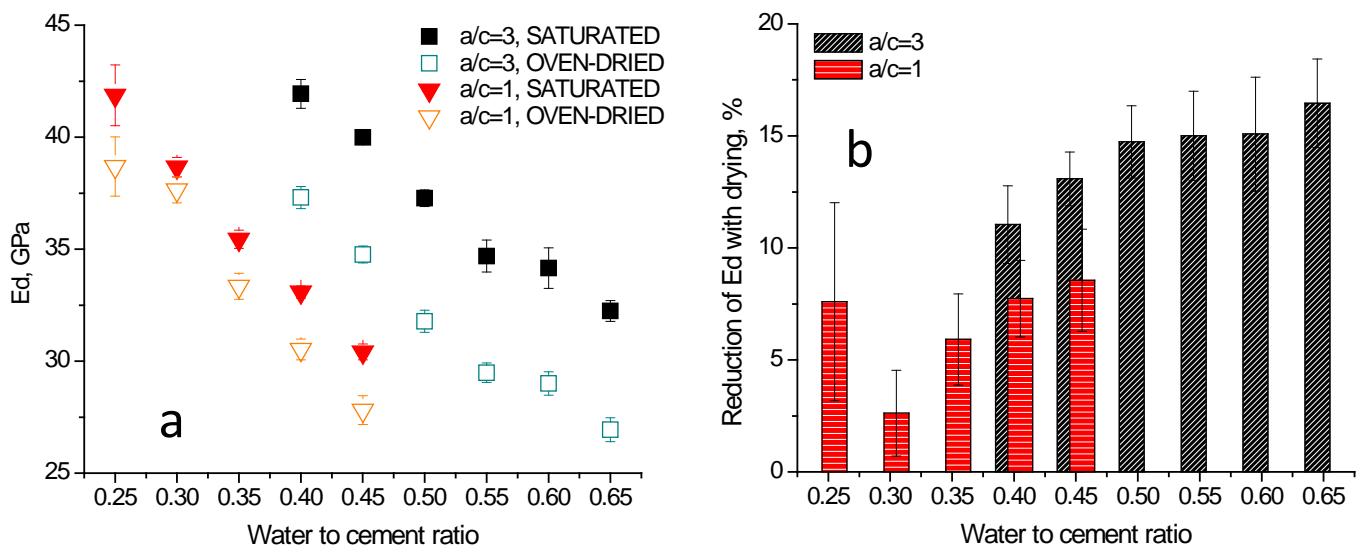

3

4

5

6

7

8

9

10

$$
\% R Q=\left(1-\frac{1 / Q_{S=0}}{1 / Q_{S=1}}\right) \cdot 100
$$

11 where $\mathrm{Q}_{s=1}$ is the $\mathrm{Q}$ in the pristine saturated state, and $\mathrm{Q}_{s=0}$ that after oven drying. At

12 saturated conditions (Figure 3a) mortars exhibit a slight inverse relation between $\mathrm{w} / \mathrm{c}$

13 and $Q$, for both a/c values. Studies have proposed that that the magnitude of damping is

14 directly related to the volume of water filled pores [32]. However, this phenomenon

15 appears to be quite minor, as the change in $Q$ value across $w / c$ values is relatively small,

16 and nearly insignificant. 

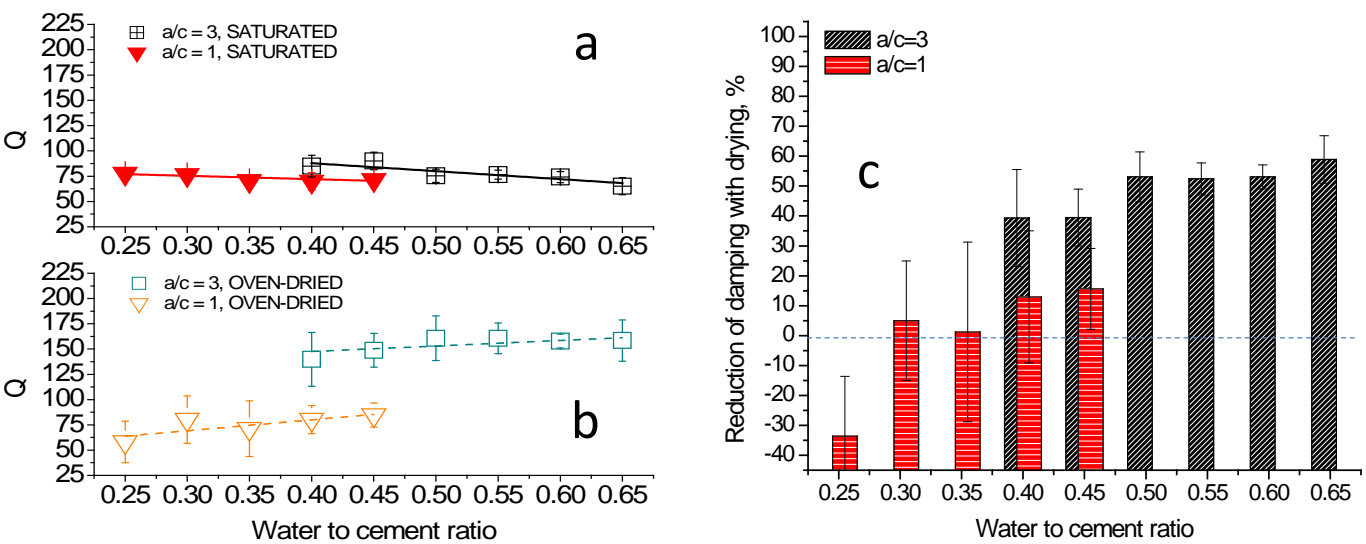

1

Figure 3. Damping properties versus water to cement ratio for a) saturated, and b) oven dried samples; continuous and dashed lines illustrate the shift from inverse towards direct proportionality after drying, c) $R Q$ for varying $w / c$. Error bars indicate standard deviation.

However, when the samples are oven-dried and all free water is removed, the dependence of $Q$ with w/c reverses sense (Figure 3b). Amick and Monteiro [33] found that damping in concrete increases (that is, $Q$ decreases) with $w / c$ for relatively early age (4-week old) concrete, but then decreases with $w / c$ for relatively mature (18-week old) concrete. Amick and Montiero attribute this behavior to the lower internal moisture content in the mature samples owing to the completion of hydration (self-desiccation), and the resulting switch of dominating damping mechanism type from viscous to Coloumb damping which in turn, strongly depends on if the loss of moisture involved generation of microcracks. In the results presented herein (Figure 3b), the reverse of sense is most likely because of lower w/c mortars developed microcracks upon drying, and hence resulting on a reverse of the trend of $Q$ with $w / c$.

In general, $Q$ values of mortars at saturated state are lower than those after oven drying. However, the samples with w/c $=0.25$ show lower $Q$ values upon drying; this behavior is discussed further in the Discussion section below. With the exception of the 
1 w/c=0.25 samples, the relative increase of $Q$ after oven drying depends, slightly, on $w / c$

2 and, more significantly, on $a / c$ as seen in Figure 3c. The increase in $Q$ with drying is

3 proportional to the $w / c$ for both values of $a / c$. For $a / c=3$ samples, the increase in $Q$ with

4 drying is significant, while for $a / c=1$ samples the increase in $Q$ with drying is modest,

5 and nearly insignificant. We attribute the relatively modest increase in $Q$ for dried

6 mortars with $a / c=1$ to increased microcracking shrinkage expected in these mortars after

7 the heat treatment, which offsets the damping reduction (that is $Q$ increase) expected

8 from the reduction of internal moisture content.

$9 \quad$ Figures $4 \mathrm{a}$ and $4 \mathrm{~b}$ show the parameter $\alpha$ for mortar samples in the saturated state

10 and after oven drying. Results for both the fundamental bending and longitudinal modes

11 are presented. The values of $\alpha$ obtained from the fundamental bending mode are

12 consistently greater than those obtained for longitudinal mode for all samples and

13 moisture states.

At saturated conditions, $\alpha$ maintains a consistently low value, and no clear relation

15 between the hysteretic parameter and $w / c$ is seen for any of the samples. However, the

16 oven-dried samples exhibit different behavior: $\alpha$ increases dramatically with decreasing $w / c$. The sources of non-classical hysteretic effects that are captured by $\alpha$ are mainly attributed to contact interactions between rough interfaces, such as those along cracks [21, 22]. The increase in $\alpha$ after oven drying suggests an increase of nonlinear sources, such as microcracks, throughout the samples. In general, mortars with $a / c$ of 1 exhibited

21 greater material nonlinearity, suggesting a greater extent of microcracking, than those with $a / c$ of 3 , and most likely due to the restraining effect of the aggregates on microcracking shrinkage, and the reduced volume of neat paste, when compared with

24 mortars with $\mathrm{a} / \mathrm{c}=1$. Regardless of $a / c$, though, the hysteretic parameter $\alpha$ increases, 25 approximately following exponential behavior as the $w / c$ decreases, and in particular 
1 higher water to cement ratio samples does not significantly increase the material

2 nonlinearity after heat treatment. Similar observations from dried concrete samples are

3 reported by Payan et al. [35]. The higher w/c studied by Payan et al. ( $w / c$ of 0.8 )

4 exhibited significantly lower hysteretic nonlinear behavior than those with lower $w / c$

5 (concrete samples with $w / c$ varying from 0.3 to 0.6 ) in the dry state.

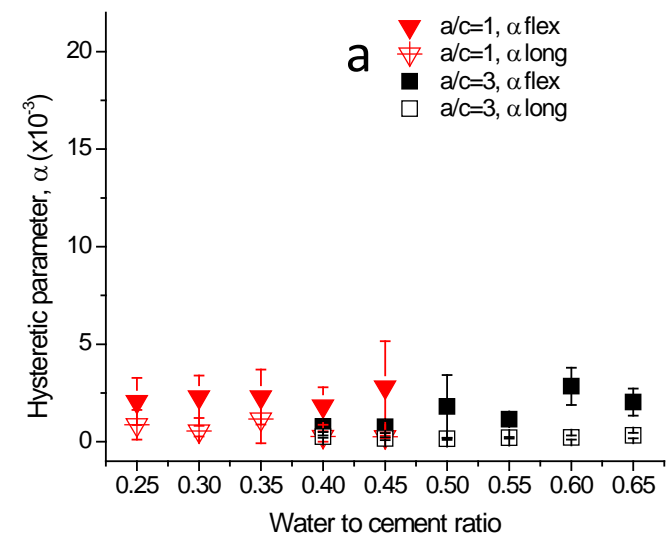

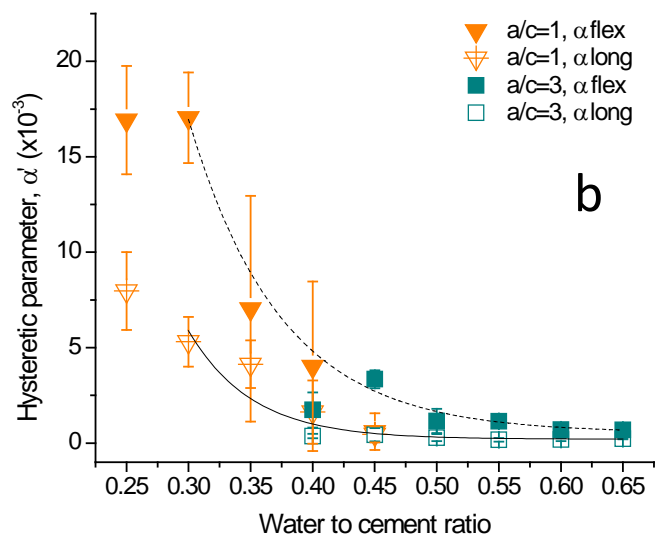

7

Figure 4. Hysteretic parameter $\alpha$ from flexural and longitudinal resonance modes for a) saturated pristine samples, and b) oven-dried samples. Dashed and continuous lines aim to guide the eye following the values of $\alpha$ for first bending (dashed) and longitudinal (continuous) modes with varying $w / c$.

\section{Discussion}

Linear $\left(E_{d}\right.$ and $\left.Q\right)$ and nonlinear $(\alpha)$ dynamic parameters are affected by both moisture content reduction and microstructural changes that are induced by drying. $E_{d}$ consistently and significantly decreases with drying, and the extent of this decrease apparently depends on capillary porosity content. After water removal with drying, the hydrostatic stiffening effect on the pore structure system is alleviated, which leads to an apparent reduction in material modulus. But furthermore, material microcracking induced by drying further contributes to the reduction of $E_{d}$. It is difficult to distinguish 
1 the contributions to the reduction of $E_{d}$ owing to the coupled microcracking shrinkage

2 and pore moisture loss effects, although it can be argued from the presented data that

3 pore moisture effects likely dominate the value of $E_{d}$ unless the extent of microcracking

4 is significantly large. Consider the anomalous behavior of the Mortar II-025 samples,

5 where an expectedly large reduction in $E_{d}$ with drying was observed. This phenomenon

6 is likely due to significantly enhanced drying and autogenous shrinkage microcracking

7 that contributes in a more equitable way to the reduction of $E_{d}$ after drying. In general,

8 autogenous shrinkage effects are more prominent in low water to binder cement-based

9 materials, and their effects extend over time. Drying at $60^{\circ} \mathrm{C}$ can promote further

10 hydration and autogenous shrinkage, especially in very low w/c mortars, even after 28

11 days of wet curing; this damage is additive to that caused by normal drying shrinkage.

12 The $Q$ and $\alpha$ parameter data for the Mortar II-025 samples also indicate greater than

13 expected levels of damage after drying. All together, these results indicate the likelihood

14 that the very low $w / c$ samples $(w / c=0.25)$ experienced notably higher microcracking

15 damage upon drying because of enhanced autogenous shrinkage effects and, further,

16 that pore moisture effects dominate $E_{d}$ values unless the extent of microcracking is

17 large.

$Q$ values and the nonlinear hysteretic parameter $\alpha$ are also affected by coupled pore

19 moisture and microcracking phenomena. However it appears that both parameters, but

20 especially $\alpha$ are more influenced by increased cracking damage than by pore water

21 removal that are caused by drying. Assuming a constant level of material microcracking

22 damage, $Q$ values are expected to be lower under dry conditions than saturated because

23 of the damping effect of the pore water. However, only the mortars with $a / c=3$ exhibited

24 notable increases in $Q$ with drying, and consistent increases in $R Q$ with higher porosity

25 (higher $w / c$ ). Mortars with $a / c=1$ displayed negligible increase in $R Q$ with drying. These 
1 materials are expected to exhibit more microcracking with drying because of lower

2 levels of internal restrain exerted by aggregates to resist drying shrinkage stresses than

3 those mortars with $a / c=3$. In fact the samples with $w / c=0.25$ exhibited a notable

4 decrease in $Q$ with drying, which as before is attributed to the extensive amounts of

5 drying and autogenous shrinkage cracking experienced by the very low w/c materials.

6 Similar to, but perhaps even more so than, the behavior of $Q$, and $\alpha$ values appear to be

$7 \quad$ largely unaffected by varying $w / c$ and $a / c$ at saturated conditions. This insensitivity to

8 capillary pore variation under saturated conditions suggests that the pore moisture effect

9 on $\alpha$ is negligible, and further that microcracking effects dominate the response. This

10 contention is supported by the notable increase in $\alpha$ with drying in cases of lower $w / c$

11 and $a / c$, where enhanced microcracking is expected.

\section{6. Conclusions}

Linear and nonlinear vibration nondestructive tests were conducted on mature mortar bar samples with varying $w / c$ and $a / c$ at pristine saturated moisture condition, and again after oven drying to stable mass at $60^{\circ} \mathrm{C}$. We expect this oven drying treatment causes significant internal moisture decrease, and also notable amounts of both microstructural modification and shrinkage cracking in the mortar. Further, we expect the amount of microstructural modification and cracking damage to increase with decreasing $w / c$ and $a / c$. The obtained results demonstrate that the linear $\left(E_{d}\right.$ and $\left.Q\right)$ and nonlinear $(\alpha)$ constitutive properties of cement-based materials are affected by the

21 oven drying treatment. However, the reduction in $E_{d}$ appears to be mostly dependent on internal moisture content, and less so on the accrued damage and microstructural

23 changes; $E_{d}$ is also affected by the aggregate cement ratio of the mixture. $Q$ and $\alpha$ 24 exhibited characteristics after oven drying treatment that suggest these parameters are 25 more sensitive to the accrued microstructural modifications and cracking, and less to the 
1 changing internal moisture content. The $\alpha$ parameter appears to show particular

effects of changing pore moisture content.

\section{Acknowledgements}

The authors want to acknowledge the financial support of the Ministerio de
Economía y Competitividad (MINECO), Spain, and FEDER funding (Ondacem Project:

BIA 2010-19933). J.N. Eiras wants to acknowledge the financial support provided by

Ministerio de Economía y Competitividad (MINECO), Spain, grant BES-2011-044624

and grants EEBB I-13-06609, and EEBB-I-14-08993 for supporting extended visits to the University of Illinois.

\section{References}

[1] O.M. Jensen and P.F. Hansen, Autogenous deformation and RH change in perspective, Cem. Concr. Res. 31 (2001) 1859-1865

[2] G.W. Scherer, Theory of Drying, J Am Ceram Soc 73 (1990) 3-14

[3] A.B. Hossain, J. Weiss, The role of specimen geometry and boundary conditions on stress development and cracking in the restrained ring test. Cement and Concr Res 36 (2006) 188-199.

[4] C. Jiang, Y. Yang, Y. Wang, Y. Zhoud, C. Mac, Autogenous shrinkage of high performance concrete containing mineral admixtures under different curing temperatures, Constr Build Mater 61 (2014) 260-269.

[5] W. Zhang, M. Zakaria, Y. Hama, Influence of aggregate materials characteristics on the drying shrinkage properties of mortar and concrete, Constr Build Mater 49 (2013) 500-510.

[6] A. Alrifai, S. Aggoun, K. Abdelkader, S. Kenai, E. Kadri, Paste and mortar studies on the influence of mix design parameters on autogenous shrinkage of self-compacting concrete, Constr Build Mater 47 (2013), 969-976.

[7] J. Bisschop, J.G.M. van Mier, Effect of aggregates on drying shrinkage microcracking in cement-based composites, Mat Struct 35 (2002) 453-461.

[8] V. Kanna, R.A. Olson, H.M. Jennings, Effect of shrinkage and moisture content on the physical characteristics of blended cement mortars, Cem Concr Res 28 (1998) 1467-1477.

[9] M. Moukwa and P.C. Aitcin, The effect of drying on cement pastes pore structure as determined by mercury porosimetry, Cem Concr Res 18 (1988) 745-752.

[10] C. Gallé, Effect of drying on cement based materials pore structure as identified by mercury intrusion porosimetry - a comparative study between oven, vacuum and freeze drying, Cem Concr Res. 31 (2001) 1467-1477.

[11] Y. Gao, J. Zhang, P. Han, Determination of stress relaxation parameters of concrete in tension at early-age by ring test, Constr Build Mat 41 (2013) 152-164.

[12] D. Zou, J. Weiss, Early age cracking behavior of internally cured mortar restrained by dual rings with different thickness, Constr Build Mat 66 (2014) 146-153.

[13] K. Van Den Abeele, W. Desadeleer, G. De Schutter, M. Wevers, Acoustic emission (AE) and nonlinear elastic wave spectroscopy (NEWS) for online monitoring of concrete curing, Adv Mat 
Res 13-14 (2006) 213-220.

[14] P. Lura, J. Couch, O.M. Jensen and J. Weiss, Early age acoustic emission measurements in hydrating cement paste: evidence for cavitation during solidification due to self-dessication, Cem Concr Res 39 (2009) 861-867

[15] J.S. Nadeau, R. Bennett, S. Mindess, Acoustic-emission in the drying of hardened cement paste and mortar, J Am Ceram Soc 64 (1981) 410-415.

[16] T.R. Naik, J.S. Popovics, The Ultrasonic Pulse Velocity Method. In: V.M. Malhorta, N.J. Carino (Eds.). Handbook on Nondestructive Test of Cocrete. $2^{\text {nd }}$ Edition, (CRC Press, Boca Raton, USA, 2004)

[17] C. Payan, V. Garnier, J. Moysan, P. A. Johnson. Applying nonlinear ultrasound spectroscopy to improving thermal damage assessment in concrete. J Acoust Soc Am 121 (2007) EL125EL130.

[18] D.G Aggelis, S. Momoki and T. Shiotani, Experimental strudy of nonlinear wave parameters in mortar, Constr Build Mat 47 (2013) 1409-1413.

[19] G. Kim, Chi-Won In, J-Y. Kim, K.E. Kurtis, L.J. Jacobs. Air-coupled detection of nonlinear Rayleigh surface waves in concrete - Application to microstructure characterization, NDT\&E Int 67 (2014) 64-70.

[20] V.M. Malhorta, V. Sivasundaram, Resonant Frequency Methods. In: V.M. Malhorta, N.J. Carino (Eds.). Handbook on Nondestructive Test of Cocrete. $2^{\text {nd }}$ Edition, (CRC Press, Boca Raton, USA, 2004)

[21] R.A. Guyer, P.A. Johnson, Nonlinear mesoscopic elasticity: evidence for a new class of materials. Phys Today 52 (1999) 30-35.

[22] K.E.A Van Den Abeele, J. Carmeliet, J.A. Ten Cate, P.A. Johnson, Nonlinear Elastic Wave Spectroscopy (NEWS) Techniques to Discern Material Damage, Part II: Single-Mode Nonlinear Resonance Acoustic Spectroscopy. Res Nondestruct Eval 12 (2000) 31-42.

[23] J. Chen, A.R. Jayapalan, J.Y. Kim, K.E. Kurtis, L.J. Jacobs, Rapid evaluation of alkali-silica reactivity of aggregates using a nonlinear resonance spectroscopy technique, Cem Concr Res 40 (2010) 914-923.

[24] F. Bouchaala, C. Payan, V. Garnier, J.P. Balayssac, Carbonation assessment in concrete by nonlinear ultrasound, Cem Concr Res 41 (2011) 557-559.

[25] J.N. Eiras, T. Kundu, M. Bonilla, J. Payá, Nondestructive Monitoring of Ageing of Alkali Resistant Glass Fiber Reinforced Cement (GRC), J Nondestruct Eval 32 (2013) 300-314.

[26] ASTM C 215:08. Standard Test Method for Fundamental Transverse, Longitudinal, and Torsional Frequencies of Concrete Specimens (ASTM, West Conshohocken, PA).

[27] EN 196-1:2005. Methods of testing cement. Determination of strength.

[28] C. Payan, T.J. Ulrich, P.Y. Le Bas, T.A. Saleh, M. Guimaraes. Quantitative linear and nonlinear Resonance Inspection Techniques and Analysis for material characterization: Application to concrete thermal damage. J Acoust Soc Am 136 (2014) 537-546.

[29] I. Yurtdas, H. Peng, N. Burlion, F. Skoczylas, Influences of water by cement ratio on mechanical properties of mortars submitted to drying, Cem Concr Res 36 (2006) 1286-1293.

[30] I.O. Yaman, N. Hearn, H.M. Aktan, Active and non-active porosity in concrete Part I: Experimental evidence, Mat Struct 35 (2002) 102-109.

[31] D.N. Winslow, D. Liu, The pore structure of paste in concrete, Cem Concr Res 20 (1990) 227235.

[32] D.N. Winslow, M.C. Cohen, D.P. Bentz, K.A. Snyder, E.J. Garboczi, Percolation and pore structure in mortars and concrete. Cem Concr Res 24 (1994) 25-37.

[33] N. Swamy, G. Rigby, Dynamic properties of hardened paste, mortar and concrete, Mat Struct 4 (1971) 13-40.

[34] H. Amick, P.J.M Monterio, Experimental determination of modal damping in concrete beams, ACI Materials Journal 103 (2006) 153-160.

[35] C. Payan, V. Garnier, J. Moysan, Effect of water saturation and porosity on the nonlinear elastic response of concrete, Cem Concr Res 40 (2010) 473-476. 